\title{
Os dois retratos de Jonathas Granville: categorias raciais e representação artística nos Estados Unidos e Haiti no século XIX
}

Bethânia Santos Pereira ${ }^{1}$

Resumo: Durante o século XIX, categorizações raciais ganharam papel cada vez mais central na definição da identidade de diferentes sujeitos e das relações por eles estabelecidas. A partir da análise de dois diferentes retratos de Jonathas Granville, representante do governo haitiano enviado aos Estados Unidos em 1824, e confrontando outros tipos de fontes, tais como periódicos da época correspondência oficial e discursos proferidos em cerimônias do governo do Haiti, o objetivo é investigar as variações das classificações raciais nos países onde as imagens foram realizadas - Estados Unidos e Haiti - a fim de compreender em que medida os retratos apresentam problematizações em torno da concepção das categorias raciais nos dois países.

Palavras-chave: Haiti; Século XIX; Jonathas Granville.

\section{Jonathas Granville's portraits: racial categories and artistic representation in the United States and Haiti in the nineteenth century}

\begin{abstract}
During the XIXth century, racial categorizations gained an increasingly central role in defining the identity of diverse subjects and the relationships they established. From the analysis of two iconographic representations of Jonathas Granville, a representative of the Haitian government sent to the United States in 1824 to negotiate the migration of AfroAmericans to the island, and with other kind of sources, such as periodicals, official correspondence and speeches given at government ceremonies in Haiti, we intend to investigate the variations of the racial classifications in the different countries where these portraits were realized - United States and Haiti - in order to understand, more than the artistic elements of each one, but how both the portraits present problematizations around the conception of the racial categories in the two countries.
\end{abstract}

Key-words: Haiti; XIXth century; Jonathas Granville.

Artigo recebido em: 25/06/2019

Artigo aprovado para publicação em: 22/10/2019

A partir de 1820, com a criação de uma sociedade filantrópica para imigração no Haiti, o presidente Jean Pierre Boyer deu seguimento a um projeto cujo objetivo era trazer ao seu país

\footnotetext{
${ }^{1}$ Mestranda, Universidade Estadual de Campinas (UNICAMP), Brasil, com a pesquisa Os códigos rurais haitianos e a invenção do trabalho livre no Haiti, 1826-1864, com financiamento da CAPES. E-mail: bethaniapereira21@gmail.com.
}

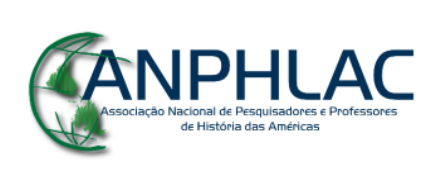


afro-americanos livres que desejassem se estabelecer na ilha. Após negociações com Loring D. Dewey, membro da American Colonization Society (ACS) em Nova Iorque, Boyer estabeleceu os termos de um acordo bastante atrativo aos imigrantes, que em troca ajudaria o Haiti a superar a ausência de mão-de-obra que afetava o país desde 1804. Em correspondências trocadas entre Boyer e Dewey, em 1824, o presidente esclareceu que o governo estava disposto a oferecer terras férteis, instrumentos de trabalho e passagens para todos que desejassem concretizar a mudança, independentemente da quantidade de pessoas. Embora a preferência de Boyer fosse por pessoas que estivessem dispostas a trabalhar no campo, imigrantes com outras qualificações, como comerciantes ou artesãos, também seriam bem-vindos e beneficiados com a isenção do primeiro ano das taxas de licença necessárias ao exercício da profissão no novo país. A cidadania haitiana estava garantida desde o início: "aqueles que vierem, sendo filhos da África, serão haitianos assim que colocarem o pé no solo haitiano" (MADIOU, 1988, p. 411).

O projeto de Boyer foi consolidado ao partir do envio de um representante do país para os Estados Unidos, Jonathas Granville, que também ocupava o cargo de comissário do governo no tribunal de cassação em Porto Príncipe. Em 13 de junho de 1824, Granville desembarcou em Nova Iorque portando cartas do presidente endereçadas a Dewey e uma certa quantidade de café que seria vendida para custear os gastos com as passagens dos novos imigrantes (ARDOUIN, 1860, p.294). A chegada de Granville levou alguma agitação à ACS por conta da disputa que se colocou entre a proposta haitiana e o já existente programa de criação da Libéria² O projeto haitiano foi bem recebido pelos afro-americanos, que o viam como uma melhor alternativa que o modelo colonizador da ACS de enviá-los para a África. Em setembro de 1824, Granville se reuniu com homens e mulheres negros e negras na Bethel Church, em Baltimore ${ }^{3}$, para falar sobre os planos de Boyer (POWER-GREENE, 2014, p.36). Foi também em Baltimore que ele encontrou o setor da ACS favorável ao Haiti, sobretudo por meio de Benjamin Lundy, quaker abolicionista e editor do Genius of Universal Emancipation.

\footnotetext{
${ }^{2}$ As diferentes posições entre os membros da ACS sobre a viabilidade do projeto haitiano fizeram com que a sociedade enfrentasse alguns problemas. Loring Dewey foi expulso da sociedade por apoiar a imigração para o Haiti, mas encontrou apoio dentre os abolicionistas de outras cidades, como em Baltimore.

${ }^{3}$ A Bethel Church foi uma igreja construída graças aos esforços dos metodistas negros de Baltimore, liderados por Charles Heckett. Foi por meio do ativismo dos membros da congregação que a cidade teve a primeira escola comandada por negros (JONES, 2018, p. 16).
}

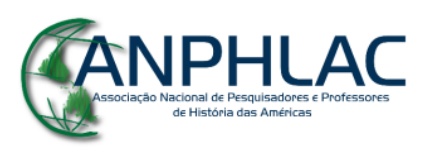


A escolha de Granville para ocupar o cargo de representante do Haiti em um país ainda escravista pode estar relacionada à sua trajetória. Quando criança, ele foi enviado à França juntamente a outros meninos, brancos e negros, para receber educação formal, às expensas do governo francês. Antes do embarque, o grupo identificado como Les élèves de la patrie participou de um jantar com Toussaint Louverture, já governador geral da ilha, que lhes disse que embora a França fosse sua pátria, era a São Domingos que eles deveriam retornar a fim de utilizarem todo o conhecimento adquirido na metrópole (MADIOU, 1988,p.331). Com a independência e o fim da relação entre França e Haiti, os meninos haitianos acabaram por encontrar outros caminhos na Europa. Granville não pôde continuar seus estudos na escola de medicina e seguiu como militar carreira na qual aparentemente foi bem-sucedido. Em 1813, tendo lutado pela França contra a Prússia, foi promovido a comandante (ARDOUIN, 1855, p.331). Após pedir baixa do exército francês, Granville passou cerca de 6 meses em Nova Iorque resolvendo problemas familiares e em 1816 retornou ao Haiti. Foi bem recebido pelo presidente da época, Alexandre Pétion. Na sua terra natal, ocupou diversos cargos: agrimensor público, professor, advogado. As amizades estabelecidas ainda durante o período colonial foram mantidas por muito tempo: em 1827, Granville representou Joseph Courtois, um dos élèves de la Patrie e, naquele momento, editor do jornal Feuille du Commerce, em uma ação contra o governo haitiano ${ }^{4}$. Ele seguiu variando entre as profissões de agrimensor, advogado e professor até 1839, quando morreu em uma situação pouco esclarecida, na cidade do Cabo Haitiano.

Parte da trajetória de Granville como pessoa pública foi registrada pelos historiadores haitianos Beaubrun Ardouin e Thomas Madiou em suas volumosas coleções de história nacional, publicadas ainda na segunda metade do século XIX. Porém, detalhes de sua vida privada estão na biografia escrita por seu filho, Jonathas Henri Theodore Granville, em 1873. Acompanhando o livro, uma gravura com o retrato de Granville pai informa que à época ele ocupava o cargo de comissário do governo no Tribunal Civil de Gonaïves, bem como que o retrato foi feito em 1839, na cidade do Cabo Haitiano. Infelizmente, o autor ainda permanece não identificado. Granville foi retratado em seu uniforme oficial e com a mão esquerda dentro

\footnotetext{
${ }^{4}$ Assim como a vida de Jonathas Granville, a trajetória da família Courtois ultrapassa limites geográficos e, como diversos haitianos, estavam transitando entre Europa e as Américas no final do século XVIII e início do XIX. A vida dos irmãos Courtois, Joseph e Sévère foi brevemente retratada por Vanessa Mongey em artigo publicado em 2012. Já a esposa de Joseph, Juliette Courtois, provavelmente a primeira mulher jornalista do Haiti, permanece quase desconhecida.
}

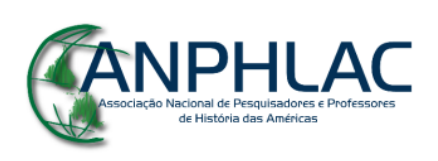


do casaco parcialmente aberto, em posição bastante difundida em retratos de personalidades políticas e pessoas com cargos importantes no decorrer dos séculos XVIII e XIX (MEYER, 1995, p.60). Na descrição fornecida pelo filho, Granville foi identificado como um mulatre, de cheveux ras et crepus, ou seja, um mulato de cabelo crespo e curto (GRANVILLE, 1873, p.15). No retrato que acompanha a obra, Granville foi representado como um homem negro de pele clara, nariz afinado e lábios pequenos, e seus cabelos, claramente não são lisos.

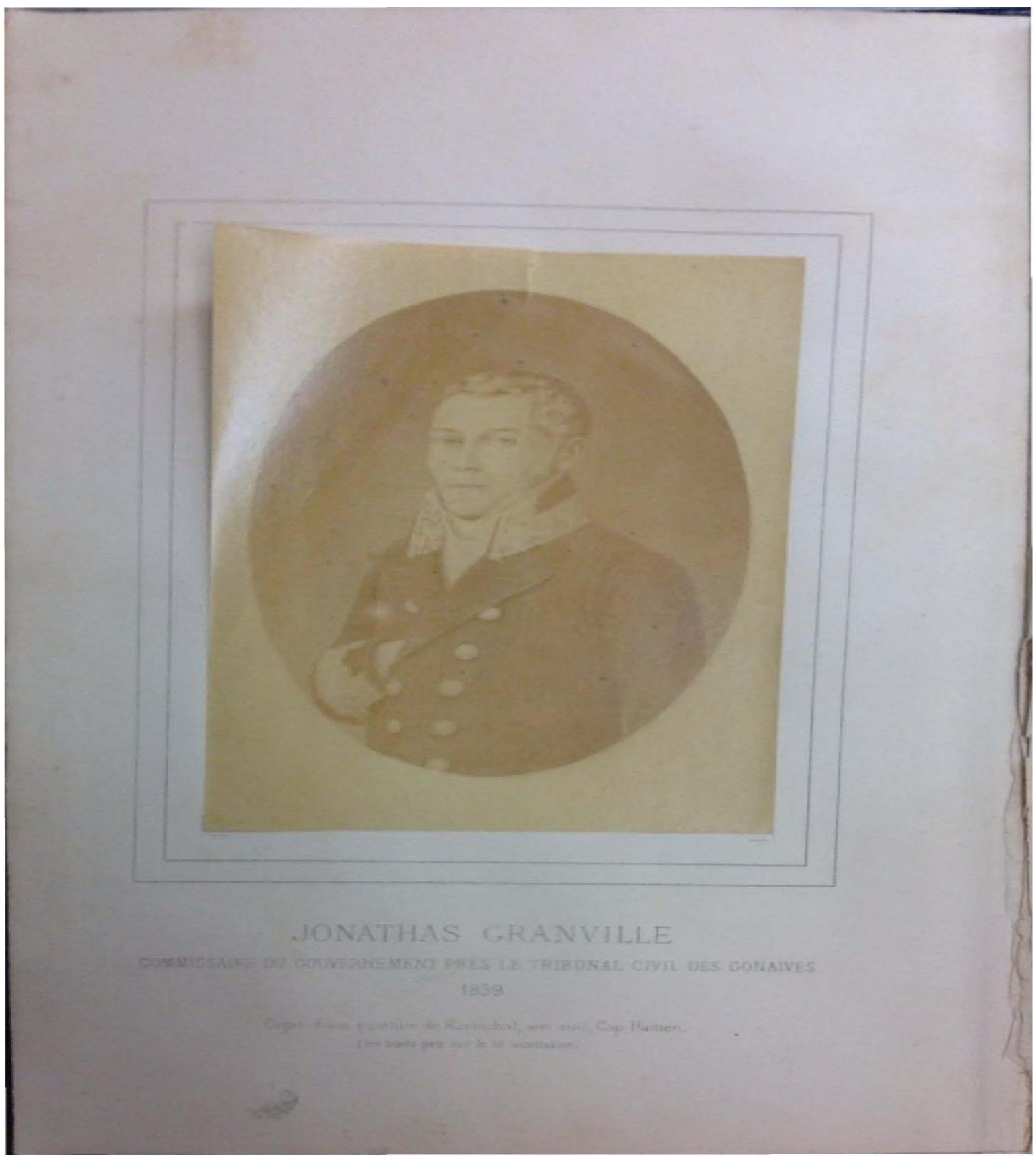

\section{GANPHLAC}


Figura 1: [Sem autor]. Jonathas Granville [gravura]. In : GRANVILLE, Jonathas Henri Théodore. Biographie de Jonathas Granville par son fils. Paris : Imprimerie E. Brière, 1873.

Mas esse não é único retrato de Granville. Entre os meses de junho e outubro de 2018, a exposição Histórias Afro-Atlânticas, realizada no Museu de Arte de São Paulo Assis Chateaubriand, trouxe dentro de um acervo com mais de 400 obras um retrato de Granville datado de 15 anos antes da sua morte, realizado por Phillip Tilyard, artista da cidade de Baltimore, nos Estados Unidos. Intitulado Portrait of the Citizen Granville, o retrato de pequenas dimensões não causaria incômodo caso não fosse tão diferente da gravura que ilustra a biografia: certamente mais jovem, Granville aparece com olhos afilados e cabelo liso, e a sua pele, evidentemente não-branca, tem um tom avermelhado. Ele não está vestido com o casaco oficial como na gravura haitiana, mas com uma camisa branca e um brinco de argola na orelha.

Diante das diferenças entre os dois retratos, o objetivo deste artigo é investigar como as distintas representações iconográficas de Jonhathas Granville estavam relacionadas às várias categorizações de raça em cada lugar e momento em ele esteve presente. A articulação dos retratos com outras fontes é utilizada como um caminho para cercar as obras por outros elementos a fim de resolver os problemas colocados por essas mesmas obras (AMANCIO, 2016, p.97). Assim, mais que apenas ilustrar a discussão ou reforçar argumentos, os dois retratos são centrais para a discussão que será apresentada. Mais que investigar se os artistas tinham alguma intenção com suas obras, o esforço neste artigo é no sentido de historicizar tais retratos para entender a relação eles e as circunstâncias em que foram criados (BAXANDALL, 2006, p. 81).

\section{CANPHLAC}




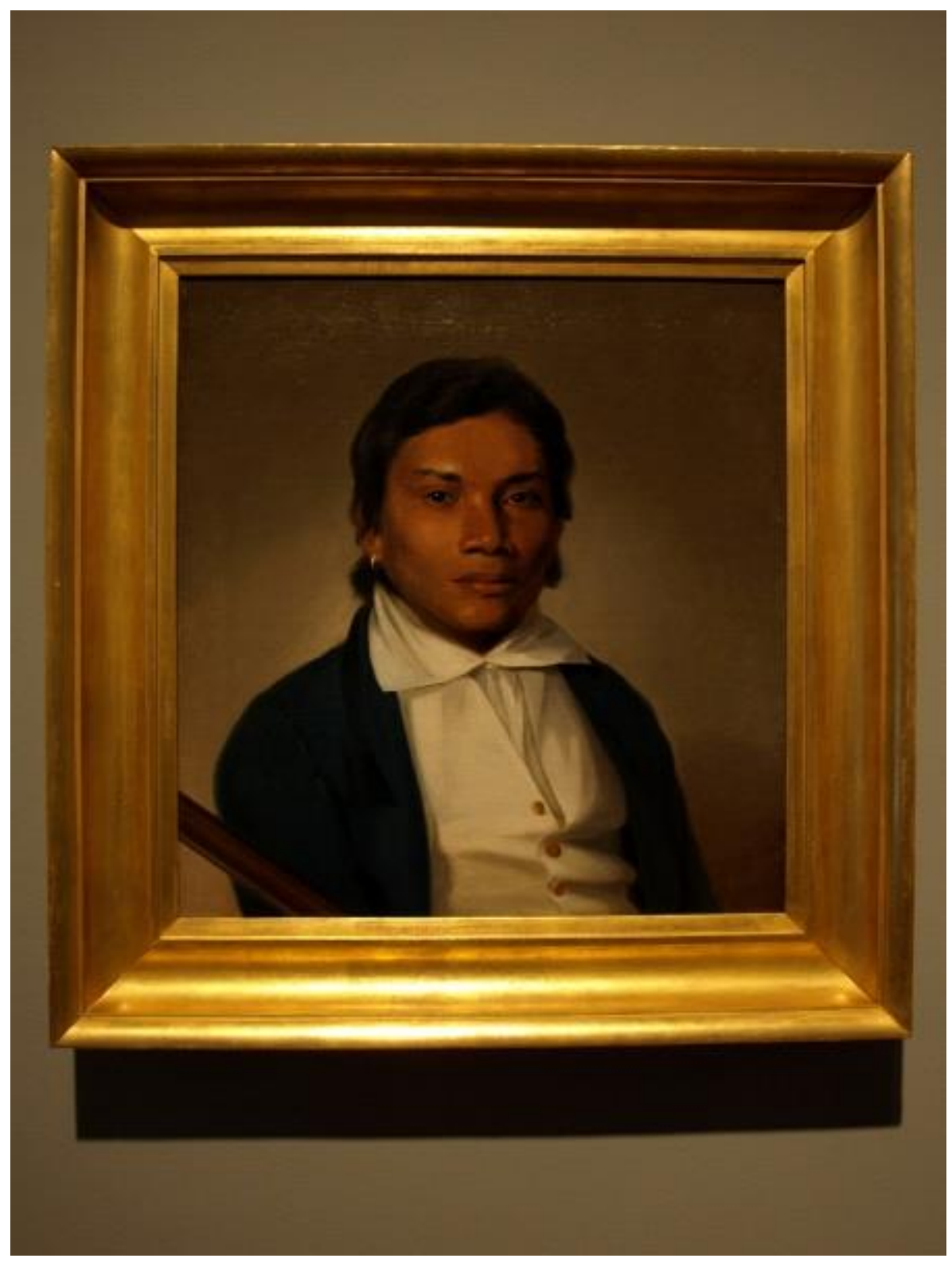

Figura. 2: TILYARD, Phillip. Citizen J. Granville. Baltimore. Óleo sobre tela. $51 \mathrm{~cm} \mathrm{X} 49 \mathrm{~cm}$. Baltimore Museum of Art, 1824.

Acerca da gravura inserida na biografia não foi possível encontrar muitas informações. A legenda da ilustração não permite muitas conclusões devido à má qualidade da cópia inserida no livro. O possível nome do autor está esvanecido e as poucas letras que podem ser vistas não parecem formar os nomes de nenhum dos pintores haitianos do século XIX já conhecidos, como Numa Desroches.

O retrato feito nos Estados Unidos, entretanto, já foi objeto de algumas análises. Sem trabalhos de grande importância em sua carreira, Phillip Tilyard morreu pobre e acabou esquecido. Porém, para sua biógrafa, a americana Helen Towley McElhiney Sharp, Tilyard foi

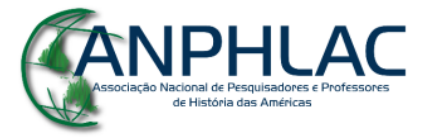


também um dos mais importantes artistas da década de 1820 em Baltimore e fazia parte da primeira geração de artistas românticos dos Estados Unidos, ao lado de retratistas como John Wesley Jarvis e Samuel Morse. A qualidade de seus trabalhos levou Tilyard a realizar retratos de pessoas influentes em Baltimore, como o comerciante de tabaco George Washington Waring e sua esposa ou os médicos Dr. John Paul Cocke e Dr. Arthur Pue. Tilyard se aproximou da pintura artística por meio do ofício de pintor de paredes e placas, que herdou do pai, imigrante da Inglaterra. Em 1812, juntamente ao irmão William, Phillip oferecia serviços de pinturas ornamentais (SHARP, 1980, p.7). Provavelmente Tilyard não teve uma educação formal em artes, mas se registrou na prefeitura de Baltimore como "pintor de retratos" em 1814 (HUNTER JR., 1950, p.394). Para o ano seguinte, 1815, Sharp localizou uma série de retratos assinados por Tilyard. Entretanto, sua trajetória como retratista não seguiu um caminho simples. Após ganhar na loteria, ele trocou o pincel pelo comércio, mas não obteve sucesso. A quantidade de dívidas acumuladas levou Tilyard à falência, fazendo com que ele perdesse sua mercearia. Foi com seu retorno à arte que ele recuperou seu nome e crédito, registrando-se assim novamente como pintor de retratos em 1822.

Na mesma época, Tilyard se mudou para uma casa ao lado do museu de arte de Baltimore, o Rembrandt Peale's Baltimore Museum and Picture Gallery, que também funcionava como galeria de arte para exposição de trabalhos contemporâneos (SHARP, 1980, p. 7). Essa mudança possivelmente fez com que Tilyard tivesse mais contato com os artistas da cidade. Além de se aproximar da produção artística de Baltimore, ele circulava entre os grupos abolicionistas da cidade. Tilyard cresceu em uma família metodista - seu nome fora escolhido em homenagem ao bispo metodista Thomas Coke, que juntamente a John Wesley difundiu ideias anti-escravidão pelas igrejas metodistas dos Estados Unidos (HARWOOD, 1962, p.287). É muito provável que a relação entre a doutrina metodista e o abolicionismo tenha sido um dos fatores que contribuiu para que Tilyard desenvolvesse um "interesse pessoal na causa da liberdade", isso pode ter sido a razão para que ele procedesse com o retrato de Granville, segundo Sharp (1980, p.14). No levantamento dos quadros pintados por Tilyard, elaborado por ela a partir dos catálogos das exposições e outros documentos, percebe-se que o retrato de Granville não foi encomendado por ninguém, mas sempre pertenceu à família do pintor, até entrar para a coleção do museu de arte de Baltimore, em 1979 (SHARP, 1980, p.145).

\section{CANPHLAC}


O envolvimento de Granville em artes também não pode ser descartado: entre 1806 e 1813, ele foi professor de dança nas cidades de Brest e Rochefort (GRANVILLE, 1873, p.16), além de ter escrito diversos poemas enquanto esteve no Haiti, Já durante sua viagem pelos Estados Unidos chegou a mencionar, em carta para Boyer, a possível compra de quadros de um artista italiano, docteur Anglesy, residente na Filadélfia. Em sua carta, Granville dispensou algumas linhas explicando os motivos das obras, a qualidade da pintura e onde elas ficariam melhor instaladas, caso o presidente decidisse adquiri-las (GRANVILLE, 1873, p.227). Porém, devido à falta de dinheiro do Estado, o presidente recusou a compra. Ainda assim, se Granville de fato encomendou seu retrato, seria no mínimo estranho que ele não o tenha levado consigo de volta para Porto Príncipe. A natureza da relação de Tilyard com a pintura também pode ser um argumento que reforça a hipótese da encomenda pelo próprio Granville: Tilyard fazia arte também para sobreviver, então talvez não fosse influenciado apenas pela causa para fazer o tal retrato. A comprovação dessas hipóteses viria com a localização de um encontro entre Tilyard e Granville. Sharp sugere que esse encontro pode ter acontecido, por exemplo, durantes as reuniões da Baltimore Emigration Society da qual, segundo ela, Tilyard era membro (SHARP, 1980, p.14). Porém, atestar tal encontro é difícil, ainda mais porque a caderneta com os agendamentos de pessoas que encomendaram retratos de Tilyard se inicia em 1827, ou seja, três anos depois da chegada de Granville.

Os registros da trajetória do quadro, desde sua concepção até a inscrição nos catálogos das exposições com as obras de Tilyard, sugere um apagamento de Granville não apenas do estúdio de Tilyard, mas da história dos Estados Unidos, e consequentemente de todo o processo de migração de afro-americanos para o Haiti:

Essa pintura foi primeiramente intitulada de "First Envoy from Santo Domingo" pela família Tilyard e datada de cerca de 1825; ao escrever para o departamento de Estado em Washington, J. Hall Pleasants não encontrou ninguém que tivesse sido enviado daquele país para os Estados Unidos até 1876; pesquisa posterior feita por Wilbur H. Hunter descobriu que o cidadão J. Granville veio para Baltimore do Haiti em 1824 (HUNTER JR. 1950, p.398).

Retirar Granville e sua viagem dos acontecimentos de Baltimore significaria desaparecer com cerca de 8 mil afro-americanos ${ }^{5}$ que decidiram se mudar para o Haiti em busca

\footnotetext{
${ }^{5}$ A quantidade de emigrantes ainda é um pouco incerta. Como citado, Power-Greene fala em quase 8 mil pessoas. Já Fanning, retomando as considerações feitas por Benjamin Hunt, ainda em 1860, fala em cerca de 13 mil emigrantes (2015, p.1).
}

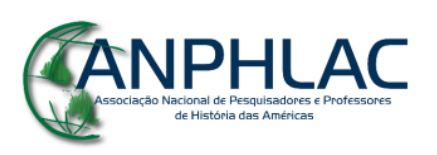


de uma vida na qual a hierarquia de cor não existisse (POWER-GREENE, 2014, p.25). Mesmo que uma certa ameaça de remoção dos Estados Unidos tenha afastado os moradores de Baltimore da proposta de migrar para o Haiti, já que por mais interessante que fosse a oferta de Boyer, os Estados Unidos eram o local de nascimento de muitas pessoas negras (JONES, 2018, p.35), é impossível descartar os efeitos da presença de um agente negro, representando uma república negra independente que oferecia um projeto construído a partir de uma identidade de raça em oposição ao planejamento quase colonizador e paternalista criado por abolicionistas brancos da ACS. As problematizações levantadas pelos debates em torno da disputa entre colonização e migração fizeram emergir questões acerca das leis e cidadania para pessoas negras em Baltimore. Em carta ao presidente Boyer, Granville atenta para as situações de preconceito que enfrentou, mesmo no norte do país:

o preconceito, embora mais fraco aqui do que no sul, não obstante, realmente existe, e mesmo na filantropia há restrições humilhantes para nós; muitos que falam em favor de pessoas de cor evitam estar na companhia deles; várias vezes fui convidado para reuniões onde sou o único da minha classe. (GRANVILLE, 1873, p.217)

Nesse sentido, Paul Gilroy está correto em afirmar que é preciso reconsiderar a posição do Haiti e da revolução haitiana no desenvolvimento do pensamento político afro-americano e das formas de resistência (GILROY, 1993, p.17). Porém, a abordagem do atlântico como um espaço de circulação de ideias, notícias, pessoas e experiências já havia sido desenvolvida por Julius Scott em sua tese de doutorado, defendida ainda em 1987, contudo, só recentemente publicada como livro. Antes que um campo de história transnacional estivesse definido como hoje, Scott trouxe a experiência de diferentes pessoas, como mulheres comerciantes, condenados fugidos, escravos marrons, negros livres, marinheiros e contrabandistas como fundamentais para a difusão de notícias e experiências desenvolvidas especificamente a partir da revolução haitiana. Essas notícias eram compartilhadas principalmente por meio da fala, entre conversas e discussões, e foi isso que ajudou a criar entre as pessoas negras um discurso público compartilhado sobre formas de resistência (SCOTT, 2019, p. 74). O projeto de Boyer e a aderência de pessoas negras a ele colocam o Haiti como uma referência positiva de liberdade e independência. O medo gerado pelo "haitianismo" teve efeitos diretos nas sociedades escravizadas, principalmente no que diz respeito ao recrudescimento da repressão. Porém, não apenas os brancos escravagistas estavam sendo informados da guerra na colônia. Ainda em 1824, o abade Henri Gregoire, abolicionista francês, escreveu que o Haiti era um farol para onde

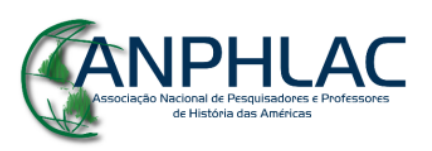


escravos e senhores, oprimidos e opressores estavam olhando. E a experiência de cada um produziu diferentes reações em relação ao que acontecia na ilha. Em seu livro mais recente, Morel investigou a repercussão da revolução no Brasil a partir de escritos que circularam entre pessoas letradas e as respostas muitas vezes positivas a essas informações (MOREL, 2017, p. 14).

A repercussão da revolução alimentou a disputa entre os dois projetos de imigração para pessoas negras o que demonstra como as redes de abolicionismo negro nos Estados Unidos eram atuantes frente às mobilizações de abolicionistas brancos. Claro que nomes como Wilberforce ou Robert Finley foram relevantes dentro do processo de fim da escravidão, mas isso coexistiu com as propostas apoiadas diretamente pelos negros. Apenas a partir do reconhecimento da pluralidade dos abolicionismos é possível entender algumas das lutas políticas que se davam naquele momento (PINTO, 2018, p.236), e que aconteciam não apenas em Baltimore e em torno do projeto de Boyer, mas em todos as sociedades que passaram pela transição da escravidão para a abolição. A circulação das ideias sobre o Haiti nas Américas acontecia desde o início da revolução, em 1793, e esteve relacionada à capacidade de ativistas negros locais em fazer essas informações circularem, principalmente como rumores, mas que frequentemente acabavam expondo e dando início às organizações que levaram a revoltas em diferentes locais (SCOTT, 2019, p. 75).

Um dos objetivos de Boyer com o projeto era ter acesso a mais mão-de-obra com a chegada dos afro-americanos, mas ele também partiu de uma genuína ideia de unidade racial que foi forjada em um passado comum de opressão. Além disso, Boyer conhecia a força política de um acordo com tais dimensões. O projeto era também uma forma indireta de forçar os Estados Unidos a reconhecerem a soberania haitiana para além de acordos comerciais informais e formar laços diplomáticos. Boyer pretendia se aproximar dos Estados Unidos por entender que esse reconhecimento implicaria em proteção contra as investidas da antiga metrópole, que ainda tentava restaurar seu poder na ilha. Por meio de um acordo, o presidente haitiano procurava ter seu país incluído na coalizão anticolonial em desenvolvimento do Novo Mundo, liderada pelos Estados Unidos, conhecida hoje como a Doutrina Monroe (FANNING, 2015, p.2). Remover o Haiti do silêncio historiográfico ou das formas de silenciamento produzidas nos arquivos não é apenas realocar Granville de volta em Baltimore, dentro ou fora do estúdio de Tilyard. É preciso recapitular como a viagem durante a qual ele passou por Nova Iorque e Filadélfia dialogou com o que já estava sendo construído nesses lugares em torno de questões sobre a cidadania negra.

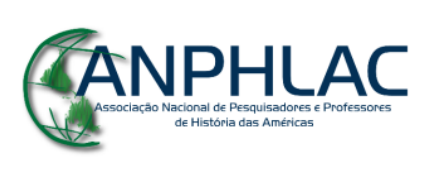


Ainda que Granville tenha circulado por vários espaços durante reuniões em Baltimore, todos os indícios levam a pensar que Tilyard fez o retrato sem a presença dele, ou seja, utilizando apenas as imagens que tinha na própria memória e auxiliado por outros elementos. A ausência de Granville para posar como modelo pode ter sido compensada pelas diferentes descrições sobre as características físicas do haitiano que Tilyard acessou por meio da imprensa da época. A chegada de Granville foi anunciada no New York Commercial Adviser do dia 18 de junho de 1824: "O agente do Hayti, como vemos agora, é um cavalheiro inteligente e bemeducado, tem a aparência de um dark mustee...”. (GRANVILLE, 1873, p. 94). Já o Nile’s Weekly Register, jornal de Baltimore, portanto com maior possibilidade de leitura por Tilyard, apresentou uma breve descrição do significado de dark mustee: "Seu nome é Granville, e ele foi visto como um cavalheiro muito bem educado e inteligente - com a aparência de um dark mustee - 'não é mais escuro do que um peruano ou mexicano'-". Não sabemos a origem da citação que explica o significado de dark mustee mas ela invoca mais elementos que podem ter contribuído para a composição criada por Tilyard.

O termo mustee tem definições bastante arbitrárias na história dos Estados Unidos. Mesmo que na maioria dos casos fosse associado à presença de uma possível ascendência indígena, as variações tornaram o significado da palavra impreciso. Strong oferece o exemplo de Nemus Killis, membro de um extenso grupo familiar que incluía nativos de diferentes etnias e que, em diversos momentos da vida foi identificado como indian e dark mustee (STRONG, 2016, p.146). Além disso, Strong atenta para o fato de que o termo poderia ser usado em combinações que fazem seus sentidos variar ainda mais: mustee, dark mustee, very dark mustee, black mustee. Cada uma dessas expressões tem um significado que era alterado de acordo com quem falava, a quem se dirigia e em que contexto era utilizada. Assim, nunca ficou muito bem definido o que implicava ser chamado de mustee, exceto que fazia referência a pessoas nãobrancas.

O antropólogo Jack Forbes tentou traçar a origem dos diferentes termos utilizados em vários lugares dos Estados Unidos para designar a população nativa. Ele associa o início da utilização de mustee aos colonizadores espanhóis, que utilizavam a palavra mestizo, que nas colônias espanholas designava as pessoas de origem europeia e americana e diferenciava as de origem afro-europeia (FORBES, 1983, p.58). Porém, nos Estados Unidos, a utilização variou bastante, podendo designar tanto as pessoas de origem afro-americana quanto as americanoeuropeias. Dessa forma, no final do século XVIII, um mustee poderia ser qualquer pessoa que

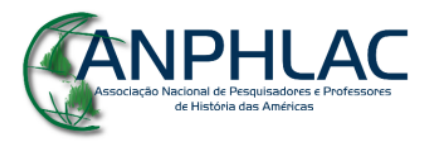


tivesse alguma origem nativa. Ainda que Forbes não seja muito categórico em afirmar que mustee indicava apenas pessoas com alguma ascendência nativa, fica evidente que, apesar das arbitrariedades do termo, um mustee poderia também ser alguém que apresentasse alguma herança genérica nativa, mesmo que fosse de negro com nativo ou europeu com nativo. Ou seja, nem todo mustee era nativo, puro ou miscigenado, mas muito provavelmente quase todos identificados como nativo eram passíveis de serem designados como um mustee. Forbes ainda chama a atenção para o fato de que em Trinidad, no Caribe, o termo mustee, já no século XIX, apontava para pessoas de origem miscigenada de europeus com nativos, diferentemente dos negros com americanos, chamados de sambos. Talvez a circulação desse tipo de informação, categorizando afro-europeus e americano-europeus em "raças" diferentes, explicaria a concordância entre as descrições dos jornais e o retrato feito por Tilyard.

Em matéria inserida no The New York Times de 1984 sobre uma exposição de arte do sul dos Estados Unidos a se realizar em Nova Iorque ainda naquele ano, o breve texto cita a importância dos artistas negros na produção de Baltimore no início do século XIX. Mais que isso, a matéria associa Tilyard e Granville a uma terceira pessoa, provavelmente um modelo negro: "O retratista negro Joshua Johnston estava em ação entre 1796 e 1824, ano em que os envolvidos nesse campo progrediram de ajudantes e servos para modelos de retrato, como no retrato feito por Phillip Tilyard de Jonathas Granville, aparentemente parte indígena”. Apesar da morte de Joshua Jones na década de $20^{6}$, foi nesse mesmo período que as organizações negras de Baltimore, sobretudo em torno das congregações metodistas de pessoas negras, adquiriram maior possibilidade de agência e cidadania. Para Martha Jones, as manifestações de cidadania negra em Baltimore estavam atacando diretamente as políticas de restrições de direitos que caracterizaram os anos anteriores à guerra da secessão (JONES, 2018, p.146). Portanto, é bastante possível que essas pessoas não estivessem apenas exercendo trabalhos domésticos, mas sim ocupando outros espaços, como o estúdio de arte. A possibilidade de que algum modelo tenha posado para Tilyard pode ajudar a completar as lacunas deixadas na descrição dos jornais e na memória do artista. O retrato de Tilyard, ainda que não se conheça todo seu projeto de

\footnotetext{
${ }^{6}$ Joshua Johnson foi um dos primeiros retratistas negros dos Estados Unidos. A confusão sobre a raça de Johnson que, por ser um negro de pele clara foi descrito como branco algumas vezes, foi desfeita quando o departamento de manuscritos da Maryland Historical's Society recebeu uma documentação do Condado de Baltimore que incluía, dentre outras coisas, a carta de alforria de Johnson (BRYAN; TORCHIA, 1996, p.3)
}

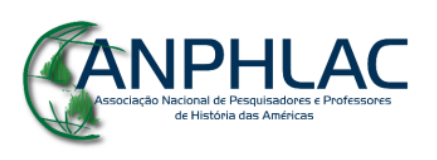


concepção e realização, levanta questões sobre como o artista interpreta e altera a realidade em que está inserido.

Além de incluir outras pessoas no processo criativo dos retratistas de Baltimore, a matéria do New York Times associa as feições de Granville àquela dos nativos. Segundo Sharp, todo o trabalho de Tilyard está ancorado no nascente romantismo que vinha da Inglaterra e começava a tomar forma nos Estados Unidos (SHARP, 1980, 49). Como não frequentou cursos regulares de artes, ele utilizou os conhecimentos de Charles Alfonse du Fresnoy, cujo livro foi encontrado entre os pertences do artista com anotações que indicam uma atenta leitura. Além de du Fresnoy, um dos artistas que mais influenciou Tilyard e com quem o autor se encontrou algumas vezes foi Thomas Sully, um dos principais nomes do retrato romântico nos Estados Unidos. Suas lições sobre o romantismo levaram o retratista de Baltimore a fazer obras que reproduzissem as feições do retratado o mais próximo da realidade, em uma tentativa de manter a semelhança. Em seu livro, Sully fala da necessidade de cerca de seis encontros com o cliente para que o retrato fosse perfeito, além da importância de sempre começar com um rascunho à lápis e não partir direto do pincel, como ensinavam outros românticos. Sully também destacou a importância do cuidado ao desenhar a boca para que o retrato fosse o mais fiel possível (SHARP, 1980, p.58). Além disso, os clientes de Tilyard tinham preferência pela manutenção da semelhança em seus retratos, seguindo uma tendência da época. Portanto, é bem provável que o Granville de traços indígenas certamente fosse uma tentativa de reproduzir algo mais próximo do "real". Porém, essa definição de realidade é bastante subjetiva, ainda mais se Granville e Tilyard realmente não se encontraram, deixando o artista com o possível modelo e com a imprensa, que identificaram Granville sob a vasta categoria de dark mustee.

Assim como em outros lugares dos Estados Unidos, o estado de Maryland nunca teve uma definição legal do que era um "negro" (BRYAN; TORCHIA, 1996, p.3). Isso podia levar a variadas conclusões sobre a condição das pessoas, como no exemplo de Ira Berlin: em 1850, Jack Coon foi registrado no censo nacional como branco, no mesmo ano, no censo do Alabama, ele aparece como negro e dez anos depois, o censo federal o classificou como nativo (BERLIN, 1976, p.161).

Retomando Jack Forbes, é possível entender como essas categorizações dependiam mais da subjetividade das pessoas brancas que as criaram que de algum conhecimento da ascendência dos não-brancos sujeitos a ela:

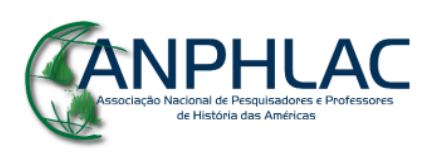




\begin{abstract}
brancos muitas vezes não conhecem a ancestralidade correta dos não-brancos e simplesmente fazem suposições, por vezes imprecisas; e (2), pode ser que se pensasse que uma pessoa de $1 / 8$ de ascendência africana e 7/8 de europeia se assemelhasse tanto a um "mestizo" de ascendência americano-europeia que as duas castas se confundiram. Da mesma forma, o que eram 3/4 africanos e 1/4 europeu foram chamados de "sambo" porque se assemelhavam a um meio-americano, meioafricano, a quem a designação era mais corretamente aplicada. É mais provável, no entanto, que todos os "mustees" e "sambos" por volta do ano de 1800 tivessem algum grau de ancestralidade americana; era simplesmente muito difícil separar com termos apropriados (FORBES, 1983, p.71).
\end{abstract}

Outra das lições de Sully pode ser bastante ilustrativa de como deveria ser a cor das pessoas não-brancas nos retratos e vai ao encontro das afirmações de Forbes: "A pele é uma parte da semelhança. As tonalidades que preparei são para uma pele clara: eu apenas reforço os tons e acrescento o red indian ao vermilion, para a pele mais escura” (BIRREN citado por SHARP, 1980, p.70). Por isso, Sharp atribuiu o retrato de Granville não apenas a uma aproximação de Tilyard com a causa abolicionista, mas como uma oportunidade utilizada por ele para experimentar novas cores e tintas (1980, p.71). Sully simplificou em branco e nãobranco todo o sistema de classificação produzido pelos colonizadores. O que não seria exatamente um problema se não fosse a observação de Forbes de que não apenas essas categorizações eram feitas com o sentido de colonizar mas como elas evidenciam o desconhecimento dos brancos de tudo aquilo que não diz respeito ao mundo branco, como essa homogeneização de não-brancos pode ser perigosa porque apaga diferentes trajetórias e ancestralidades. Assim, Sully nos dá pistas de como não havia um conhecimento unificado sobre o que era ser não-branco, por parte dos brancos, mas apenas um imperativo de dominação e controle que separava brancos de não-brancos.

A diferença entre as descrições físicas de Granville nos escritos haitianos e americanos é indicativa da variedade das classificações de raça. Seu filho o descreveu como um mulâtre em diferentes momentos. Nos livros de Ardouin e Madiou ele nunca foi identificado como indígena ou nativo. Quando Granville, ainda adolescente, embarcou para a França no grupo das crianças de Louverture, ele também era mulâtre. Na tradução em francês, conduzida por Granville filho, dos recortes dos jornais americanos que reportaram a chegada do seu pai, o termo dark-mustee foi transformado em quarteron-brun. A taxonomia de Saint-Méry pode nos ajudar com isso. Segundo a categorização de Moureau de Saint Méry, um mulâtre era o filho

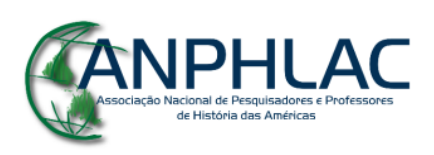


de homem branco com mulher negra, uma négresse ${ }^{7}$. Porém, de acordo com a biografia, Granville é filho de Simon Pierre Granville, francês, com a mulâtresse Marie-Therese Anne Labrosse. Seguindo à risca a organização de Saint-Méry, Granville seria um quarteron, como aparece na tradução de Granville filho e não um mulâtre.

Porém, uma suposta origem indígena de Granville continuaria quase impossível de ser atestada, independentemente da classificação: dentre as mais de 120 categorizações identificadas por Saint-Méry, os indígenas são aproximados dos mulâtres: "Como sua nuance [dos indígenas] é a mesma do Mulâtre, suas combinações têm exatamente os mesmos resultados, exceto os cabelos que são menos crespos do que nas combinações que se aproximam do negro..." (SAINT-MÉRY, 1797, 74). Ou seja, pela fórmula de Saint-Méry, a utilização da palavra mulâtre por Granville filho poderia designar tanto uma origem ameríndia-europeia quanto afro-europeia. Além disso, a explicação de Saint-Méry indica que a ascendência indígena em São Domingos tinha implicações diferentes de uma ascendência negra ou branca: a partir do momento em que a ancestralidade indígena não fosse mais pura, ela não tinha relevância e, diferentemente das heranças negra e branca, que poderiam ser adquiridas em frações e constituíam categorias fundamentais na decisão da raça, a herança indígena não contribuía muito para a constituição racial (PERRY, 47, 2017).

Talvez o caso de Granville seja como o do historiador Thomas Madiou, que sempre foi identificado como mulâtre, mas declarou em sua autobiografia ser filho de uma mulher indígena (Élie citado por Geggus, 1997, p.62). Ou seja, é possível que descendentes de indígenas, ao contrário do que postula uma historiografia mais tradicional, estivessem sim circulando pelo Haiti do século XIX e, em muitos casos, em posições influentes. O próprio Madiou afirmou que o desaparecimento dos nativos Taíno aconteceu não por meio do extermínio, mas da miscigenação e assimilação. (MADIOU, 1988, p.237). Pode ser, então, que a categoria de mulâtre seja muito mais fluida e complexa que apenas a prole resultante da união de brancos/as e negros/as. Sendo assim, a única certeza que temos até aqui é de que a palavra mulâtre indica miscigenação. Encontrar a origem da mãe de Granville talvez trouxesse alguma luz sobre essas

\footnotetext{
${ }^{7}$ O historiador francês Médéric Louis Élie Moureau de Saint Méry, nascido na Martinica, criou uma taxonomia das categorizações raciais na ilha de São Domingos. No seu livro Déscription Topographique, Physique, Civile Politique et Histoire de la Partie Française de L'isle Saint-Domingue, publicado no final do século XVIII, ele apresenta tabelas que categorizam as pessoas sob 128 classificações a partir da cor da pele, segundo a sua ascendência.
}

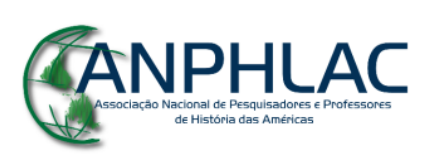


questões, mas, por outro lado, evidenciaria ainda mais as arbitrariedades das categorias raciais e como a variedade em cada contexto político pode gerar diferentes conclusões. Para esclarecer o caso, é importante considerar também os cargos que Granville ocupou.

Além de ter sido o enviado de Boyer aos Estados Unidos, Granville ocupou a posição de comissário do governo no tribunal de Santo Domingo, no lado leste da ilha de Hispaniola quando a região estava toda unificada. A escolha de Boyer por Granville pode também ser atribuída à sua qualificação para o cargo, mas a resistência dos dominicanos à identidade africana já é discussão na historiografia, sobretudo para o século XX quando os miscigenados daquele lado da ilha eram oficialmente chamados de mestizos ou índios (GEGGUS, 1997, p.55). Mas a ocupação do lado espanhol da ilha pelo Haiti não foi um processo calmo, como Madiou descreveu. Boyer conhecia as querelas entre Nuñes de Cáceres, líder de um dos movimentos independentistas da República Dominicana, e os grupos dos hateros, parte da elite dominicana (BRYAN, 2018, p. 158) sendo que, aproveitando-se do conflito, ofereceu vantagens econômicas aos últimos, tais como a extinção do imposto sobre a exportação de gado, em troca de suporte para expansão dos territórios haitianos. Contudo, em nenhum momento esse grupo reivindicou alguma identidade africana ou se colocou ao lado do Haiti em nome de uma abolição transnacional (MOYA PONS, 2013, p.23).

Os conflitos desse processo ficaram um pouco evidentes no discurso que Granville realizou em fevereiro de 1823, durante seu período em Santo Domingo (GRANVILLE, 1873, p.67). Ele se dirigiu diretamente aos funcionários do judiciário - maioria dominicanos - pedindo que fizessem valer as leis haitianas naquele lado território e tivessem empenho suficiente para superar os problemas da linguagem, já que as diferenças entre o espanhol e o francês, bem como a reduzida quantidade de pessoas falantes dos dois idiomas, ou mesmo um deles, geraram problemas administrativos ao governo de Boyer. Conhecendo a resistência dos dominicanos, talvez o presidente tenha optado por um "mulato" com pouco fenótipo negro para tentar algum diálogo com o lado mais resistente do país. Diferentemente do Haiti, a reivindicação por uma identidade Taíno, adquirida tanto por meio da cultura quanto por vias biológicas, é bastante comum em outras ilhas do Caribe e se opõe à visão exagerada de que os indígenas foram completamente exterminados pela colonização.

Todavia, tal identificação no lado espanhol da ilha também estava associada à marginalização ou negação da negritude (PERRY, 2017, p. 48). A resistência dos espanhóis à identidade africana já havia sido apontada por Madiou, ainda no século XIX. Ao comentar as

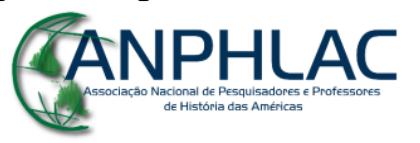


estratégias de aproximação utilizadas por Boyer para se conectar ao lado espanhol recém anexado, ele afirma que o presidente sempre tentava trazer elementos europeus em suas falas mas que ele só podia agir dessa forma naquele lado da ilha onde "a maioria dos habitantes se dizia branca ou indígena, ainda que eles fossem miscigenados de brancos, indígenas e africanos de todas as cores" (MADIOU, 1988, p.373)

Quando traduziu os recortes de jornais americanos na biografia do pai, Granville não traduziu dark-mustee como mulâtre. Ele, o filho, foi muito específico em utilizar a expressão quarteron-brun. E é nessa tradução que os sentidos se alteram. Se mulâtre, ainda que seja difícil de traçar seu significado e sua utilização por misturar conceitos de raça e classe intimamente relacionados à conjuntura haitiana, a tradução de Granville tem relação com o vocabulário haitiano que chegou na ilha por meio da colonização, em uma tentativa de esclarecer a utilização norte-americana das palavras ao leitor haitiano. Embora não tenha sido possível, por enquanto, determinar de que forma Granville filho estava sendo informado das categoriais raciais dos Estados Unidos, algumas considerações podem ser levantadas acerca do vocabulário racial francês.

Ao descrever os indígenas do Chile, La Pérouse utilizou o termo brun para se referir à cor da população: “A cor da pele é de um brun avermelhado...” (1797, 37). Na descrição feita por Desmaret para se referir aos índigenas brasileiros, ele também utiliza a palavra com o mesmo sentido que La Pérousse, a fim de dizer que as pessoas daquele lugar tinham a pele de "une couleur brune". Mas isso não parece necessariamente indicar uma classificação étnica ou de raça. Assim como o dark-mustee norte-americano é bastante incerto - e indica mais uma miscigenação que algo definido - a versão em francês escolhida por Granville filho não esclarece muita coisa.

No Grand Dictionnaire Universel du Siècle XIX, a palavra brun aparece associada à raça e não como uma variante da miscigenação, mas apenas no sentido de ser uma palavra que indica uma cor de cabelo ou para indicar uma tonalidade, "como algo que tem uma cor entre o amarelo e o preto" (LAROUSSE, 1867, p. 1343). No dicionário, brun tem o mesmo sentido que brown, de ser "apenas" uma cor. Diferentemente de noir, que indica, além da cor, também "aquele que pertence à raça dos negros" (LAROUSSE, 1874 p.1052). Curiosamente, o exemplo para o noir, no mesmo dicionário, é a pessoa com a pele très brune, ou seja, de um marrom intenso. E o quarteron, assim como na explicação de Saint-Méry, designa alguém proveniente da união de mulato/a com branco/a (LAROUSSE, 1875, p. 502). Porém, diferentemente dos exemplos

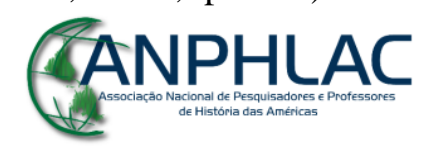


anteriores dos viajantes que descreviam os indígenas da América do Sul com essa palavra, o dicionário já pertence ao século XIX e o registro do vocábulo e seus significados indica que ela já estava em circulação há algum tempo, sendo que os sentidos que apareciam na oralidade nem sempre são apreendidos pelo texto.

Embora o dicionário não tenha feito os sentidos das palavras mais evidentes, ele demonstrou como a utilização da palavra variava. Na verdade, essas explicações não levam a muitas conclusões nem sobre o uso de mulâtre nem brun, talvez porque indicassem exatamente o que estivesse sem muita definição. A confusão pode ser inerente à utilização desses termos, não apenas porque essas categorizações partiram de brancos sem conhecimento das diferenças entre aqueles que não eram brancos, mas porque o acréscimo de advérbios que tentavam esclarecer ou escurecer a cor de cada um poderia significar pertencimento a diferentes grupos. Ao comparar os esquemas coloristas de Brasil e do Haiti, Labelle propõe que as ambiguidades em torno de termos como moreno e mulato têm uma função ideológica dentro dos grupos nos quais aparecem. Não parecia ser diferente para Granville, Madiou ou outros mulâtres que, em razão do discurso nacionalista do país, trouxeram suas origens indígenas para a incerta categoria do "mulato", mas que dentro de um país cuja formação como estado nacional dependia do conflito racial, e que só nasceu da guerra entre negros e brancos, a manutenção da rivalidade, e dos indivíduos que construíram essa disputa, era fundamental para a existência do discurso nacionalista. Ser o "não-branco" já indicaria a oposição ao branco europeu colonizador e, consequentemente, garantiria espaço legítimo e pertencimento dentro da República Haitiana.

Labelle investigou as associações de raça e classe no vocabulário haitiano e suas conclusões, embora sejam referentes ao século XX, trazem indicações que podem ser úteis. Elas definem tanto o mulâtre, quarteron e brun quanto categorias específicas, sendo o primeiro usado para pessoas com "pele amarela ou cor de café com leite, cabelos finos, retos e sedosos, características finas. Os burgueses fazem dela uma categoria muito diversificada" (1987, p.132). Já o quateron é usado para se referir a pessoas com a "pele amarela ou muito clara, cabelos lisos, linhas finas" (1987, p.133). Finalmente, o termo brun referenciava aqueles com a pele de cor “castanha, com cabelos que variam de 'bastante crespo'... a cabelo liso, características variáveis" (1987, p.132). Apesar da tentativa da pesquisadora de criar classificações que tivessem alguma objetividade, assim como no trabalho de Saint-Méry, as categorias ficam confusas e com significados aparentemente intercambiáveis. Labelle consegue identificar

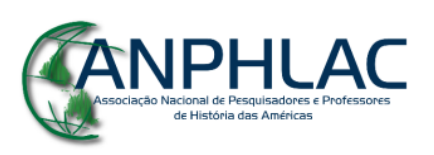


melhor os sujeitos que pertencem à cada categoria quando os cruza com as informações de classe não só de quem é classificado, mas também de quem classifica.

Se no lado republicano, a referência a uma identidade indígena ou branca - ou a miscigenação delas - era uma estratégia recorrente de pessoas negras, no Haiti acontecia outro movimento. A localização dos indígenas na história do Haiti tem sido um desafio atual para a historiografia, embora a discussão não seja nova. As perspectivas mais difundidas e tradicionais seguem as narrativas nacionais: todos os indígenas foram assassinados pelos europeus. Alguns trabalhos, porém, tentaram combater essas visões. Autores como Maya Deren (1975) e Louis Maximillien (1992) buscaram nos aspectos religiosos elementos que demonstrassem alguma influência indígena no Haiti. Ainda assim, essas investigações não foram muito conclusivas. Amanda Perry analisa como o uso da palavra indigène pelos haitianos desde o início do século XIX indicava uma categoria que incluía negros, tanto os nascidos na ilha quanto os vindo da África, mas era principalmente uma categoria que excluía os brancos. A declaração de independência assinada por Dessalines foi feita em nome do "exército indígena" (PERRY, 2017, p. 53). Segundo Fischer, a utilização da palavra estava mais conectada aos sentidos políticos e que atestava o pertencimento àquele território que uma identidade racial (FISCHER, 2004, p. 242). Tanto Fischer quanto Perry afirmam que a reivindicação pelo território e garantia da soberania eram os elementos principais na criação de um discurso indigenista no Haiti (PERRY, 2017, p .61).

No Haiti, um pouco diferente da situação dos Estados Unidos, as categorizações não dependiam apenas de como as pessoas brancas dividiram as não-brancas. Obviamente, o sistema de Saint-Méry ainda aparece em alguma medida, mas com a independência, o colorismo das 128 categorias desapareceu e deu lugar a uma divisão entre negros e mulatos que não diz respeito apenas à cor da pele, mas cada termo expressa os contextos políticos e sociais que lhes deram origem em diferentes momentos e espaços de formação de um sistema de hierarquia racial. Na Constituição haitiana de 1805, o artigo 14 indicava que "todos os Haitianos serão identificados apenas sob a genérica denominação de "negros"'. Diferentemente da forma como Saint-Méry relaciona nativos e mulatos apenas pela cor da pele, a decisão de Dessalines transformou em categoria política o que ainda estava sendo definido como uma categoria biológica como forma de diminuir as disputas raciais do país (GAFFIELD, 2007, p. 90). A negritude dos cidadãos correspondia ao pertencimento à nação e evidenciava a cor como meio de lealdade a um projeto específico de liberdade e independência (DUBOIS, 2010, p. 51) Nesse

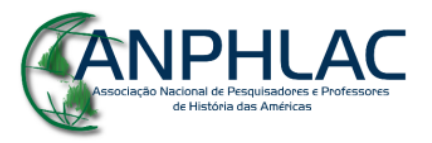


processo, os possíveis descendentes indígenas desapareceram no discurso de unidade nacional e na criação de uma nova definição de pertencimento que equiparava cidadania e negritude.

Na constituição de 1843, novamente os descendentes dos indígenas são retomados, mas para lhes atribuir a nacionalidade haitiana. Diferentemente da constituição de Dessalines, em 1843 o Haiti já não precisa mais do discurso de liberdade transnacional como no início do século XIX, tampouco lhe é mais possível se utilizar de tal recurso contra os outros países, já que as pressões das grandes potências, sobretudo França e Estados Unidos, fizeram com que o país tivesse de se ajustar, mesmo que com dificuldade, ao modelo corrente de estado-nação limitado pelas fronteiras decididas ainda durante o período colonial (FISCHER, 2004, p. 241). Naquele momento, segundo a nova constituição, todos os cidadãos eram haitianos, sem qualquer indicação de cor, raça ou etnia. Se Granville tinha de fato uma ascendência indígena, dificilmente saberemos, pois esta não fora registrada. Dentro do projeto nacional do Haiti, não havia um espaço para os nativos. Nas palavras de Saint-Méry, o lugar dos indígenas era o da miscigenação, ao lado dos mulatos. Utilizando apenas a cor de pele como referencial, o francês da Martinica não foi capaz de perceber a diversidade de experiências que separava um nativo de um negro escravizado. Porém, dentro da criação do estado nacional haitiano, talvez essa classificação, e possível exclusão dos nativos, não tenha acontecido de forma tão arbitrária e violenta quanto a francesa.

A escolha do nome em Taíno para o país está relacionada ao total rompimento da Revolução Haitiana com a ordem colonial e à retomada do momento pré-colonização como indicador do futuro do país. Mas os nativos são incluídos na narrativa nacional do Haiti como parte do passado, o que certamente não se deve à ausência de pessoas descendentes desses grupos. Em sua estadia no Haiti, o jamaicano Richard Hill notou a presença de descendentes de nativos na região do distrito de Artibonite: “a população deste distrito é uma bela raça de pessoas... o sangue dos indígenas, assim como o africano, se misturam em suas veias, sendo mais aparente na fluidez e textura do cabelo do que no contorno das feições, embora seja perceptível” (The Anti-Slavery Reporter, p. 232, 1831).

Uma das poucas narrativas haitianas que incluem os Taíno como parte da história do país é o livro de Émile Nau, Histoire des Caciques d'Haiti, publicado em 1837. A história da resistência dos indígenas contra a colonização, liderados pelo cacique Henri, torna-se uma alegoria da Revolução Haitiana, sendo assim, nativos e africanos estão relacionados não por tradições ou valores compartilhados, mas a partir da mesma luta pela liberdade. Nas palavras

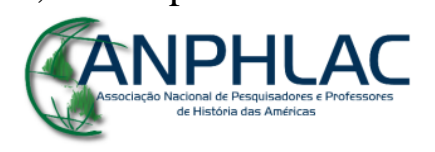


de Nau, "o africano e o americano uniram as mãos através das correntes" (NAU, 1837, p.14). A diferença entre a luta nativa e a africana é que os últimos tiveram sucesso, de forma que se tornaram os legítimos herdeiros da terra dos Taíno. A ausência de nativos nas narrativas haitianas contribuiu para justificar a posse da ilha por parte dos ex-escravizados e reforçar a soberania do país a partir da continuidade da luta contra os colonizadores.

$\mathrm{Na}$ introdução do livro, Nau afirma que a posse da terra veio por meio da servidão compartilhada com os povos nativos: "Por herdarmos sua servidão, nós também herdamos sua terra natal" (1837, p.14). O pertencimento não foi construído em termos de herança a partir da família e do sangue, ou da raça, mas sim na condição comum de explorados dos africanos e nativos e na luta contra a França. Ao terminar a guerra, Dessalines teria dito que, naquele momento, ele havia vingado a América (JENSON, 2011, p. 46).

Durante a assinatura da declaração da independência, quando foi escolhido o nome do país, mais de 2/3 dos 37 oficiais que assinaram o documento eram de origem miscigenada e nenhum deles era apenas africano (GEGGUS, 1997, p.45). Além disso, muitos haviam estudado na metrópole e mantinham alguma conexão com a França. Para Geggus, foi essa origem letrada que fez com que essas pessoas escolhessem por um nome americano já que, além da perspectiva da vingança de Dessalines, o nome em Taíno expressava também o rompimento total com a França, mas ao mesmo tempo um afastamento da África (GEGGUS, 1997, p.55). Por mais que os haitianos não negassem suas origens africanas e estivessem em clara luta contra o colonialismo, nunca houve uma reivindicação pelo retorno às "origens" africanas. Para o Haiti, a África é um espaço de selvageria e ausência de civilização, em um discurso muito parecido com os argumentos encampados por Alex Crummel (APPIAH, 2007, 43).

$\mathrm{Na}$ carta de instrução que Boyer enviou para Granville contendo as indicações sobre como proceder nos estados Unidos, ele afirma que o projeto da ACS era "impraticável porque esses países [africanos] eram insalubres e povoados por nações ainda bárbaras" (GRANVILLE, 1873, p.89). Contudo, considerando a diversidade que parece estar abrigada sob o nome de mulâtre, talvez aquelas 37 pessoas que assinaram a declaração de independência estivessem fazendo referência a algo que eles realmente conheciam, a uma experiência comum de convivência com elementos indígenas que de fato faziam parte do cotidianos deles e não apenas expressão de um conhecimento adquirido por meio da leitura, como sugere Geggus. Mas essa possível diversidade do termo também indicava que as características étnicas nem sempre

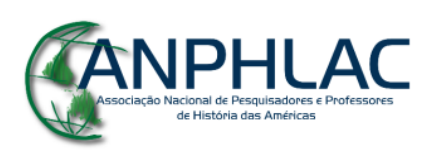


correspondiam à identidade atribuída a cada pessoa (SCHWARTZ, 1997, p. 5). Diversos outros elementos atuavam na definição de quem era quem.

A tentativa de descrição feita por Tilyard e outros americanos que souberam da existência de Granville expõe a não universalidade dos termos relacionados à raça e, ao mesmo tempo, a possibilidade de intercâmbios das classificações. No momento em que Granville saiu do Haiti, onde suas possíveis características nativas estavam abrigadas sob o termo mulâtre, foi transformado em qualquer outra coisa que só era possível partir do vocabulário e das experiências étnicas dos Estados Unidos, de Baltimore ou de Tilyard. A fluidez das categorias pela qual Granville é transportado fica ainda mais evidente por ele ser alguém que não pertencia à lógica daquele espaço, no caso dos Estados Unidos. Porém, no caso do Haiti, a presença de Granville não causava nenhum problema de definição. Ele era mulâtre e isso não parecia ter gerado discussão em Porto Príncipe, Santo Domingo ou no Cabo Haitiano.

O desafio que se coloca é entender quem poderia ser chamado de mulâtre e por quê. Portanto, mais que descobrir, por meio dos retratos, se Granville tinha alguma ascendência indígena, é importante pensar como essas categorias mobilizavam conceitos sociais e conhecimentos compartilhados sobre quem era quem e como eram expressados nas diferentes representações artísticas feitas dele. Complexa, primeiramente, porque reivindicar uma identidade negra ou indígena tinha implicações políticas reais no contexto haitiano do século XIX. A identidade nacional haitiana foi definida a partir de valores associados à masculinidade e, sobretudo, à negritude. As derivações de termos como "mulato" não estavam tão relacionadas às características físicas quanto com seus significados políticos no contexto da independência e da garantia da soberania haitiana frente aos outros países. Esconder ou não a possível ascendência nativa de Granville e outros haitianos revela muito mais sobre o próprio país que sobre a identidade desses indivíduos. Analisar a presença dos indígenas no Haiti é uma tarefa complexa e ultrapassa os limites deste trabalho. O que fica evidente a partir dos dois casos é que a confusão com o uso dos termos e das classificações se repete em diferentes espaços, mas tomam contornos distintos a partir das variadas intenções políticas de quem mobiliza tais categorias.

\section{GANPHLAC}




\section{Referências Bibliográficas}

\section{Fontes}

BEAUBRUN, Ardouin. Études sur l'histoire d'Haiti. Tome 1. Paris: Dézobry, E. Magdeleine, 1855 .

BEAUBRUN, Ardouin. Études sur l'histoire d'Haiti. Tome 9. Paris: Dézobry, E. Magdeleine, 1860.

LAROUSSE, Pierre. Grand Dictionnaire universel du XIXe siècle. Paris : Larousse et Boyer, 1866-90. 17v.

SAINT-MÉRY, Médéric Louis Elie Moureau de. Déscription Topographique, Physique, Dupont Libraire, 1797.

GRANVILLE, Jonathas Henri Théodore. Biographie de Jonathas Granville par son fils. Paris: Imprimerie de E. Brière, 1873.

MADIOU, Thomas. Histoire d'Haiti. 1811 - 1818. Tome V. Port-au-Prince: Éditions Henri Deschamps, 1988

Histoire d'Haiti. 1819 - 1826. Tome VI. Editions. Port-au-Prince: Henri Deschamps, [1847] 1988.

The Anti-Slavery Reporter

Nile's Weekly Register

\section{Bibliografia}

AMANCIO, Kléber. Reflexões sobre a pintura de Arthur Timoteo da Costa. 2016. Tese (Doutorado em História). Faculdade de Filosofia, Letras e Ciências Humanas, Universidade de São Paulo, São Paulo, 1989.

APPIAH, Kwame Anthony. Na casa de meu pai: a África na filosofia da cultura. Rio de Janeiro Contraponto, 1997.

BAXANDALL, Michael. Padrões de intenção: a explicação histórica dos quadros. São Paulo: Companhia das Letras, 2006.

BERLIN, Ira. Slaves without masters: the free negro in the Antebellum South. New York: Vintage Books, 1976.

BRYAN, Jennifer; TORCHIA, Robert. The Mysterious Portraitist Joshua Johnson. Archives of American Art Journal, vol. 36, no. 2, p. 3-7, 1996.

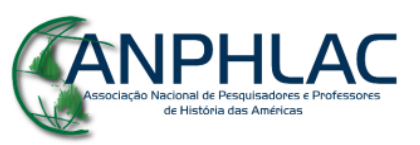


DEREN, Maya. The voodoo gods. Saint-Albans: Paladino, 1975.

FISCHER, Sibylle. Modernity disavowed: Haiti and the cultures of slavery in the age of revolution. Durham: Duke University Press, 2004.

FORBES, Jack D. Mustees, Half breeds and Zambos in Anglo North America: Aspects of Black-Indian Relations. American Indian Quarterly, vol. 7, n.1, p. 57-83, 1983.

GAFFIELD, Julia. Complexities of Imagining Haiti: a Study of National Constitutions, 1801 1807. Journal of Social History p. 81-103

GEGGUS, David. The Naming of Haiti. NWIG: New West Indian Guides. v. 71, n. 1/2, p. 4368, 1997.

GILROY, Paul. The Black Atlantic: Modernity and Double-Consciousness. Cambridge: Harvard University Press, 1993.

HARWOOD, Thomas F. British Evangelical Abolitionism and American Churches in the 1830's. The Journal of Southern History, vol. 28, no. 3, p. 287-306, 1962.

HONOUR, Hugh (ed). The image of the black in Western art (v.4 pt.1). Cambridge: Harvard University Press, 1989.

HUNTER JR, Wilbur H. Philip Tilyard. The William and Mary Quarterly, v. 7, n. 3, p. 393 405, 1950.

JENSON, Deborah. Beyond the Slave Narrative: Politics, Sex, and Manuscripts in the Haitian Revolution. Liverpool: Liverpool University Press, 2011.

LABELLE, Micheline. Idéologie de couleur et classes sociales en Haïti. Montréal: Les Presses de l'Université de Montréal, 1987.

MAXIMILLIEN, Louis. Quelques apports indiens dans la vie haïtienne. In : CHARLES, Phillipe Christophe (org.). Christophe Colomb, les indiens et leurs survivances en Haïti. Portau-Prince: Christophe, 1992.

MEYER, Arline. Re-dressing Classical Statutary: The Eighteenth-Century "Hand-InWaistcoat" Portrait. The Art Bulletin, v. 77, n. 1, p. 45-63, 1995.

\section{CANPHLAC}


MONGEY, Vanessa. A Tale of Two Brothers: Haiti's Other Revolutions. The Americas, v. 69, n. 1, p. 37-60, 2012.

MOREL, Marco. A Revolução do Haiti e o Brasil escravista: o que não deve ser dito. Jundiaí: Paco Editorial, 2017.

MOYA PONS, Frank. La dominación haitiana, 1822 - 1844. Santo Domingo: Librería La Trinitaria, 2013.

PERRY, Amanda T. Becoming Indigenous in Haiti: from Dessalines to La Revue Indigène. Small Axe. v. 21, n. 53, 2017. p. $45-61$.

PINTO, Ana Flávia Magalhães. Escritos de Liberdade: literatos negros, racismo e cidadania no Brasil oitocentista. Campinas: Editora da Unicamp, 2018.

POWER-GREENE, Ousamane K. Against wind and tide - The African American Struggle against the Colonization Movement. New York: New York University Press, 2014.

SCHWARTZ, Stuart B. Spaniards, 'pardos', and the missing mestizos: identities and racial categories in the early Hispanic Caribbean. NWIG: New West Indian Guides. v. 71, n. 1/2, p. 519, 1997.

SCOTT, Julius. The Common Wind: Afro-American Currents in the Age of the Haitian Revolution. London; New York: Verso Books, 2018.

SHARP, Helen Towley McElhiney. Philip Thomas Coke Tilyard: Baltimore Portraitist. Dissertação (Mestrado em Artes). Universidade de Delaware, 1980.

STRONG, John A. The Unkechaug Indians of Eastern Long Island: A History. University of Oklahoma Press, 2016.

\section{CANPHLAC}

